Original Research Article

\title{
Knowledge, attitude, perceptions and assessment of effectiveness of educational intervention on Pharmacovigilance among undergraduate medical students at Gulbarga Institute of Medical Sciences, Kalaburagi, India
}

\author{
Harish G. Bagewadi, Priyadarshini M. Deodurg*, B. V. Patil, Asha P. Dass
}

Department of Pharmacology, Gulbarga Institute of Medical Sciences, Kalaburagi,

Karnataka, India

Received: 01 November 2017 Accepted: 24 November 2017

\section{*Correspondence to:}

Dr. Priyadarshini M. Deodurg, Email: dr.priyadarshinideodurg @ gmail.com

Copyright: (C) the author(s), publisher and licensee Medip Academy. This is an openaccess article distributed under the terms of the Creative Commons Attribution NonCommercial License, which permits unrestricted noncommercial use, distribution, and reproduction in any medium, provided the original work is properly cited.

\begin{abstract}
Background: The Study was designed to assess the awareness of Pharmacovigilance and to evaluate the impact of an educational intervention. Methods: This was a questionnaire-based pre- and post-test educational interventional study. Students were given handouts containing information about pharmacovigilance one month before the educational intervention. A prevalidated 20-point questionnaire on (KAP) Knowledge, attitude, perception about Pharmacovigilance was distributed to second year medical students $(n=115)$. An interactive educational intervention (Power point presentation) was designed. The chi-square test and unpaired paired t-test was used for statistical calculation. Results: The overall response rates were expressed as percentages, Mean \pm SD. The knowledge, attitude and perceptions of pharmacovigilance when compared before (pre-KAP) and after (post-KAP) the educational intervention, the correct response rates were found to be statistically significant $(\mathrm{P}<0.001)$. The feedback from the students was encouraging, handouts before the lecture classes helped them to easily grasp the pharmacovigilance concepts better during lectures.

Conclusions: The study concluded that imparting the knowledge about pharmacovigilance and ADR reporting promotes drug safety and rational use of medicines in future.
\end{abstract}

Keywords: Attitude, Knowledge, Perceptions, Pharmacovigilance

\section{INTRODUCTION}

The safety of patients and the safe use of medicines are high requisitions in the modern world. In 1968, the first practical international co-operation in drug monitoring was established. The ideas came up as a consequence of the so called thalidomide tragedy. In the 1960's it was discovered that if thalidomide is ingested by mothers during pregnancy limb deformities in babies may occur. This incident became the modern starting point of a science focusing on patient problems due to medicinal use. Medication safety is a more significant issue, because of immense competition among pharmaceutical manufacturers; medicinal products may be registered and marketed in many countries simultaneously. As a result, adverse reactions may not always be readily identified and so are not monitored systematically. Pharmacovigilance has constantly grown its importance in last 15 years, relating to the absolute amount of adverse drug reactions (ADRs) and to the fact of several hospital admissions are due to ADRs. ${ }^{1,2}$ Pharmacovigilance is an arm of patient care and surveillance. It aims at getting the best outcome from treatment with medicine. Adverse drug reactions (ADRs) are common causes of morbidity and mortality in both hospital and community settings. Adverse drug 
reactions (ADRs) are global problems of major concern. ADRs are responsible for about $5 \%$ to $20 \%$ of hospital admissions. ${ }^{3,4}$ World Health Organization (WHO) defines ADR as "any response to a drug which is noxious and unintended, and which occurs at doses normally used in man for prophylaxis, diagnosis, or therapy of disease, or for the modification of physiological function".

Studies from different settings indicate inadequate knowledge about pharmacovigilance among healthcare professionals as well as attitude that are associated with high degree of underreporting. ${ }^{5-10}$ Assessment of awareness of Pharmacovigilance among the healthcare professionals is very important due to under reporting of adverse drug reactions. Ensuring the safe use of drugs is a combined responsibility of the healthcare team that includes Doctors, Nurses, Pharmacists and other supporting staffs. $^{11}$ As future medical practitioners, medical students need to be well trained on how to recognize, prevent and report ADRs. Therefore, the aim and objective of this study was to evaluate knowledge, attitude and the perceptions about Pharmacovigilance among medical students at medical college in south India by an interactive educational module as an intervention.

\section{METHODS}

The study was conducted at Gulbarga Institute of Medical Sciences, Kalaburagi. Permission was duly taken from Institutional Ethics Committee to conduct the study. This was a prospective, Knowledge, Attitude and Practice (KAP) questionnaire based study. Second year $(n=115)$ medical students, were participated in the study. Before the educational intervention was conducted, students were given handouts containing information about pharmacovigilance one month before the intervention. Semi-structured, pre-validated, questionnaire was used for data collection as a research tool. A structured questionnaire was designed after minor modifications. ${ }^{12,13}$ The KAP questionnaire consisted of 20 questions about pharmacovigilance. Out of which, 11 questions were related to knowledge, 05 questions were related to attitude, 04 questions were related to perception. The correct responses were scored 1 point and wrong responses were given zero point for knowledge related questions and practice related questions. The attitude related questions were scored based upon the participant's degree of agreement using Likert scale. The score was as following; " 0 "- strongly disagree, " 1 "- disagree, "2"- uncertain, " 3 "agree and " 4 "-strongly agree. In order to preclude any potential bias, the disclosure of name of the responder was made optional.

Before the start of educational intervention, initially all the students were briefed about the purpose of the study, student's consent was taken; later pre-KAP questionnaire was administered and asked to submit the same. An interactive educational intervention was designed in the form of power point presentation for one hour by trained faculty to all participants of Pre-KAP questionnaire survey in order to facilitate the transfer of knowledge of pharmacovigilance. The educational intervention consisted of a theoretical presentation on what is pharmacovigilance, its main objectives, adverse drug reactions reporting, Vigiflow database, classification of ADRs, incidence of ADRs, role of health care professionals, reporting of suspected adverse drug reaction followed by economic and epidemiological importance of reporting the ADRs and its effect on patient safety and causality assessment of ADRs. After the interactive educational intervention program on pharmacovigilance, all participants of Pre-KAP questionnaire in the study was administered with Post-KAP questionnaire and it was analyzed, question wise and their responses were documented.

The filled KAP questionnaires were evaluated as per the study objectives, the KAP scores were analyzed. The data obtained were entered in Microsoft excel spread sheet and evaluated. The impact of effectiveness of educational intervention on the awareness of pharmacovigilance among the second year medical students is evaluated. The chi-square test and unpaired t test was used to compare the difference in correctness for each question. All results attained were entered in Microsoft excel and the statistical calculations were executed using Graph Pad Instat. The $p$ value $(\mathrm{p}<0.05)$ is considered to be statistically significant.

\section{RESULTS}

All the answers are expressed in terms of numbers, percentages and Mean $\pm \mathrm{SD}$, for the KAP questionnaire (Pre-KAP and Post-KAP) comprising of 20 questions was evaluated and tabulated in Tables 1, 2, 3, 4 and Figure 1.

Question 01 of Table 1, emphasized on the role of health care professionals in ADR reporting, for which the comparativeness with educational intervention in between pre-KAP (22\%) and post-KAP $(88.7 \%)$ revealed effective educational intervention with statistically significance ( $p<0.0001)$.Question 03 from Table 1 framed to obtain the information about objectives of pharmacovigilance where in pre-KAP $(25.5 \%)$ and post-KAP (76.6\%) and statistically significant $(\mathrm{p}<0.0001)$ correct responses were evident after educational programme. This data suggests that continuing educational intervention is an important tool for increasing all health care professionals' awareness to pharmacovigilance. Based on our study results recommend including "pharmacovigilance" as a topic in continuing education programmes and would also recommend a yearly repetition of such educational interventional program to all health care professionals. ${ }^{14,15}$

Question 04 from Table 1 is framed to obtain the information about the international center for reporting of ADR's and Question 06 from Table 1, about databases on ADR reporting system, it was found that there was an increased positive response rate of $7.8 \%$ as pre-KAP to $74.7 \%$ post-KAP and $8.6 \%$ as pre-KAP to $7.8 \%$ post-KAP after the educational intervention program respectively. 
The result strongly suggests that students were greatly influenced by the educational intervention regarding the reporting systems of ADRs both of national and international standards which is in accordance with earlier study. ${ }^{16}$

Table 1: Knowledge of pharmacovigilance before and after educational intervention.

\begin{tabular}{|c|c|c|c|c|}
\hline $\mathbf{Q}$ & K A P - Items & $\begin{array}{l}\text { Pre-KAP } \\
\text { score n }(\%)\end{array}$ & $\begin{array}{l}\text { Post-KAP } \\
\text { score n }(\%)\end{array}$ & $\begin{array}{l}\text { p- } \\
\text { value }\end{array}$ \\
\hline 1. & $\begin{array}{l}\text { The healthcare professionals responsible for reporting ADR in a hospital } \\
\text { is/are- } \\
\text { a) Doctor b) Pharmacist } \\
\text { c) Nurses d) All of the above* }\end{array}$ & $26(22)$ & $102(88.7)$ & $\mathrm{p}<0.0001$ \\
\hline 2. & $\begin{array}{l}\text { Define Pharmacovigilance? } \\
\text { a) The science of monitoring ADR's in the Hospital } \\
\text { b) The process of improving the safety of Drugs } \\
\text { c) The detection, assessment, understanding } \\
\text { and prevention of adverse effects } \\
\text { d) The science of detecting the type } \\
\text { and incidence of ADR after drug is marketed. }\end{array}$ & $35(30.4)$ & $86(74.7)$ & $\mathrm{p}<0.0001$ \\
\hline 3. & $\begin{array}{l}\text { The important objective of Pharmacovigilance is } \\
\text { a) To identify safety of drugs* } \\
\text { b) To calculate incidence of ADR's } \\
\text { c) To identify predisposing factors to ADR's } \\
\text { d) To identify ADR's occurring at high doses }\end{array}$ & $12(10.4)$ & $92(80)$ & $\mathrm{p}<0.0001$ \\
\hline 4. & $\begin{array}{l}\text { The international center for adverse drug } \\
\text { reaction monitoring is located in: } \\
\text { a) Unites States of America b) Australia } \\
\text { c) Canada d) Sweden* }\end{array}$ & $9(7.8)$ & $86(74.7)$ & $\mathrm{p}<0.0001$ \\
\hline 5. & $\begin{array}{l}\text { Which of the following scales is commonly } \\
\text { used to assess the causality of an ADR? } \\
\text { a) Hartwig scale b) Schumock and Thornton scale } \\
\text { c) Naranjo algorithm* d) Karch and Lasagna scale }\end{array}$ & $8(6.9)$ & $80(69)$ & $\mathrm{p}<0.0001$ \\
\hline 6. & $\begin{array}{l}\text { Which one of the following is the 'WHO } \\
\text { online database' for reporting ADRs? } \\
\text { a) ADR advisory committee b) Med safe } \\
\text { c)Vigibase" d) Med watch }\end{array}$ & $10(8.6)$ & $90(78)$ & $\mathrm{p}<0.0001$ \\
\hline 7. & $\begin{array}{l}\text { Rare ADRs can be identified in the following phase of } \\
\text { a clinical trial: } \\
\text { a) phase- } 1 \text { clinical trials b) phase- } 2 \text { clinical trials } \\
\text { c) phase- } 3 \text { clinical trials d) phase- } 4 \text { clinical trials }\end{array}$ & $11(9.6)$ & $100(86.9)$ & $\mathrm{p}<0.0001$ \\
\hline 8. & $\begin{array}{l}\text { Select the correct (ADR and its causative drug) option: } \\
\text { a) Phocomelia- Streptomycin } \\
\text { b) Hemolytic anemia- Thalidomide } \\
\text { c) HPA axis suppression - Ofloxacin } \\
\text { d) Cleft lip- Phenytoin* }\end{array}$ & $16(13.9)$ & $84(73)$ & $\mathrm{p}<0.0001$ \\
\hline 9. & $\begin{array}{l}\text { Select the correct (ADR and its causative drug) option: } \\
\text { a) Yellowish discoloration of teeth- Isotretinoin } \\
\text { b) Ebstein's cardiac anomaly- Warfarin } \\
\text { c) Neural tube defects- Valproic acid* } \\
\text { d) depressed nose, hand defects- Lithium }\end{array}$ & $18(15.6)$ & $78(67.8)$ & $\mathrm{p}<0.0001$ \\
\hline 10. & $\begin{array}{l}\text { Regarding classification of ADR, the correct option is: } \\
\text { a) Type A is predictable, dose related } \\
\text { b) Type B is Unpredictable, dose unrelated } \\
\text { c) Both a) and b) are correct" } \\
\text { d) None of the above }\end{array}$ & $14(12.1)$ & $70(60.8)$ & $\mathrm{p}<0.0001$ \\
\hline 11. & $\begin{array}{l}\text { It is important to report ADRs leading to- } \\
\text { a) Hospitalization b) congenital abnormality } \\
\text { c) patient death d) All of the above* }\end{array}$ & $26(22.6)$ & $70(60.86)$ & $\mathrm{p}<0.0001$ \\
\hline
\end{tabular}


The study also focused on assessing the attitude of medical students- ADR's reporting in question 14 and 15 Table 2, which reveled to be $20.8 \%$ before pre-KAP to $90.4 \%$ post-
KAP, $14.7 \%$ before pre-KAP to $67.8 \%$ post-KAP respectively, which strongly suggests that students need to undergo educational sessions on ADR's reporting. ${ }^{17}$

Table 2: Attitude of pharmacovigilance before and after educational intervention.

\begin{tabular}{|c|c|c|c|c|}
\hline Q. & K A P Items & $\begin{array}{l}\text { Pre-KAP } \\
\text { Score n }(\%)\end{array}$ & $\begin{array}{l}\text { Post-KAP } \\
\text { Score n }(\%)\end{array}$ & p- value \\
\hline 12. & $\begin{array}{l}\text { Do you agree that ADR reporting system would benefit patient } \\
\text { care? -Strongly agree* }\end{array}$ & $30(26)$ & $90(78.2)$ & $\mathrm{p}<0.0001$ \\
\hline 13. & $\begin{array}{l}\text { Would you suspect ADRs when drug is administered in normal } \\
\text { dose? -Disagree* }\end{array}$ & $18(15.6)$ & $80(69.5)$ & $\mathrm{p}<0.0001$ \\
\hline 14. & $\begin{array}{l}\text { Reporting of all ADRs for a new drug is essential? } \\
\text {-Strongly agree* }\end{array}$ & $24(20.8)$ & $104(90.4)$ & $\mathrm{p}<0.0001$ \\
\hline 15. & $\begin{array}{l}\text { Do you agree reporting of adverse drug reaction } \\
\text { is necessary? -Strongly agree* }\end{array}$ & $17(14.7)$ & $78(67.8)$ & $\mathrm{p}<0.0001$ \\
\hline 16. & $\begin{array}{l}\text { Do agree Pharmacovigilance should be taught in detail to } \\
\text { healthcare professionals? -Strongly agree }\end{array}$ & $22(19.1)$ & 102 (88.6) & $\mathrm{p}<0.0001$ \\
\hline
\end{tabular}

Table 3: Perception of pharmacovigilance and after educational intervention.

\begin{tabular}{|c|c|c|c|c|}
\hline Q. & K A P Items & $\begin{array}{l}\text { Pre-KAP } \\
\text { Scores n }(\%)\end{array}$ & $\begin{array}{l}\text { Pre-KAP } \\
\text { Scores n }(\%)\end{array}$ & $\begin{array}{l}\text { p- } \\
\text { value }\end{array}$ \\
\hline 17. & $\begin{array}{l}\text { Is it important to know national, international centers for ADR } \\
\text { monitoring? -Yes* }\end{array}$ & $12(10.4)$ & $76(66)$ & $\begin{array}{l}\mathrm{p}<0.00 \\
01\end{array}$ \\
\hline 18. & $\begin{array}{l}\text { Communication of safety information between all health care } \\
\text { professionals can minimize the risk of marketed medicines? -Yes* }\end{array}$ & $16(13.9)$ & $80(69.5)$ & $\begin{array}{l}\mathrm{p}<0.00 \\
01\end{array}$ \\
\hline 19. & $\begin{array}{l}\text { Can ADR monitoring help to promote rational use of medicines? - } \\
\text { Yes }^{*}\end{array}$ & $13(11.3)$ & $78(67.8)$ & $\begin{array}{l}\mathrm{p}<0.00 \\
01\end{array}$ \\
\hline 20. & $\begin{array}{l}\text { Would you like to read an article (online /newspaper/Magazine) } \\
\text { about ADR's in future? -Yes* }\end{array}$ & $16(13.9)$ & $86(74.7)$ & $\begin{array}{l}\mathrm{p}<0.00 \\
01\end{array}$ \\
\hline
\end{tabular}

Correct Response*, $\mathrm{P}<0.001$ (comparison between the pre- KAP and Post- KAP responses).

Table 4: Student feedback regarding educational intervention on pharmacovigilance.

\begin{tabular}{|c|c|c|}
\hline Students opinions: & Response & n (\%) \\
\hline $\begin{array}{l}\text { Sought information about } \\
\text { Objectives of Pharmacovigilance- }\end{array}$ & Yes* & $\begin{array}{l}102 \\
(88.6)\end{array}$ \\
\hline $\begin{array}{l}\text { Sought information about Vigiflow } \\
\text { database for adverse drug reactions } \\
\text { monitoring- }\end{array}$ & Yes $^{*}$ & $\begin{array}{l}78 \\
(67.8)\end{array}$ \\
\hline $\begin{array}{l}\text { Sought essential information } \\
\text { required while reporting an ADR- }\end{array}$ & Yes $^{*}$ & $\begin{array}{l}106 \\
(92.1)\end{array}$ \\
\hline $\begin{array}{l}\text { Sought information about different } \\
\text { types of ADR- }\end{array}$ & Yes $^{*}$ & $\begin{array}{l}98 \\
(85.2)\end{array}$ \\
\hline $\begin{array}{l}\text { The hand-outs before the lecture } \\
\text { helped us to grasp the ADR } \\
\text { monitoring and Pharmacovigilance } \\
\text { concepts during lecture better- }\end{array}$ & Yes $^{*}$ & $\begin{array}{l}112 \\
(97.3)\end{array}$ \\
\hline $\begin{array}{l}\text { Handouts before every } \\
\text { Pharmacology lecture class helps } \\
\text { to absorb concepts better- }\end{array}$ & Yes* $^{*}$ & $\begin{array}{l}110 \\
(95.6)\end{array}$ \\
\hline $\begin{array}{l}\text { The photo images showing some } \\
\text { examples of (ADR's and its } \\
\text { causative drug) during lecture were } \\
\text { informative- }\end{array}$ & Yes $^{*}$ & $\begin{array}{l}94 \\
(81.7)\end{array}$ \\
\hline
\end{tabular}

n- Number of Yes*responses, (\%) - percentage of responses
The study is focused on assessing the perception of ADR reporting centers in question 17 Table 3 , which revealed to be $10.4 \%$ before pre-KAP to $66 \%$ post-KAP, which also points to the importance of impact of educational interventions on Pharmacovigilance in accordance. ${ }^{17}$

Question 20 from Table 3, to read an article (online /newspaper/Magazine) about ADR's in near future revealed to be $34.1 \%$ before pre-KAP to $74.5 \%$ post-KAP, this type of enthusiasm, motivation gained among students after educational intervention is a very positive response to be acknowledged.

\section{DISCUSSION}

The study showed that medical students who attended the interactive educational intervention on Pharmacovigilance were much satisfied, and considered more effective and valuable. In our study, one focus of educational intervention was to increase the medical students awareness to Pharmacovigilance, regulatory bodies responsible for monitoring of ADR's, types of ADR's. This was demonstrated by an increase in the correct 
responses in pre and post-KAP questions (1 to 20) about pharmacovigilance and ADR's reporting with statistical significance $(\mathrm{p}<0.0001)$, after the educational intervention highlighting the impact on its effectiveness.

Questions 08 and 09 from Table 1 are framed to obtain the knowledge about ADR and its causative drug which medical students, physicians must know to promote safe and rational use of medicines. The response rate is $13.9 \%$ as pre-KAP to $73 \%$ post-KAP and $15.6 \%$ as pre-KAP to $67.8 \%$ post-KAP respectively, after the educational intervention program. Question 10 from Table 1, shows response rate from $12.1 \%$ pre-KAP to $60.8 \%$ post-KAP which strongly suggests that the information about different types of ADR, and question 11 from Table 1, infers about when to report ADR's and practical knowledge on ADR from $22.6 \%$ pre-KAP to $60.86 \%$ postKAP improved enormously after educational intervention. Question 12 from Table 2, showed that $26 \%$ before preKAP to $78.2 \%$ post-KAP, and Question 13 from Table 2 showed that $15.6 \%$ before pre-KAP to $69.5 \%$ post-KAP strongly suggests that there is a great need to create awareness on attitude aspect of ADR reporting among medical students can be done by continuous medical education programs on pharmacovigilance.

In Figure 1, the total Pre-KAP scores on knowledge (11.6 \pm 2.15$)$, attitude $(22.3 \pm 1.66)$, perception $(14.1 \pm 1.29)$ when compared to total post- KAP scores on knowledge (35 \pm 2.12$)$, attitude $(41 \pm 3.21)$, perception $(56.3 \pm 1.32)$ respectively, the overall increase in correct response rate with statistical significance $(\mathrm{p}<0.0001)$ was observed after educational intervention.



Figure 1: Mean KAP scores of responders-Overall level of knowledge and attitude among the participants $(n=115)$.

Earlier studies by authors has also shown that enhancing knowledge, attitude, and perception of improving awareness can increase the number of ADR reports. ${ }^{16,17}$ This study which stated that a main reason for under reporting of ADRs was the clinical negligibility of the adverse reaction due to lack of time and little knowledge about the types of reactions to be preferentially reported..$^{18}$ Similar study shows, where hands outs were given one week before in the previous study. ${ }^{19}$ However, in a similar educational interventional program in pharmacovigilance study, showed that educational intervention improved awareness of pharmacovigilance on knowledge, attitudes, practice of healthcare professionals. ${ }^{20}$

The feedback from the students was encouraging and positive. The hand outs before the lecture classes helped them to understand the concepts better and potentiated easy grasping habits during lecture hours. Students are of the opinion that handouts when given before every Pharmacology lecture would help them to absorb concepts better during lecture classes. The photo images showing some examples of (ADR's and its causative drug) during lecture class, made students to learn ADR's causality effectively and to assess benefit/risk ratio of marketed medicines.

This study has two important limitations. Firstly, the study period was too short. Secondly, the study findings could not be applied to the wider community medical students and other health care professionals as the study was restricted to second year medical students in department of Pharmacology, Gulbarga Institute of Medical Sciences, Kalaburagi. Therefore authors recommend that several such studies of similar kind should be conducted among wider community medical students as well as to all types of health care professionals so as to develop strategies to improve the knowledge, attitudes, practice of pharmacovigilance in India and globally.

\section{CONCLUSION}

In conclusion, the results of the present study demonstrate that an educational intervention can increase awareness of pharmacovigilance among the medical students and inculcate in their future clinical practice. The medical students would be made aware about benefit- risk ratio of safety of marketed medicines and importance of communication with various health care professionals in pharmacovigilance.

\section{ACKNOWLEDGEMENTS}

The authors would like to thank all the second year medical students for their enthusiasm in their participation.

Funding: No funding sources

Conflict of interest: None declared

Ethical approval: The study was approved by the Institutional Animal Ethics Committee

\section{REFERENCES}

1. Von Laue NC, Schwappach DL, Koeck CM. The epidemiology of preventable adverse drug events: a review of literature. Wien Klin Wochenschr, 2003;115(12):407-15. 
2. Wu WK, Pantaleo N. Evaluation of outpatient adverse drug reactions leading to hospitalization. American Journal of Health System Pharmacy. 2003;60(3):2539.

3. Lazarou J, Pomeranz BH, Corey PN. Incidence of adverse drug reactions in hospitalized patients: A meta analysis of prospective studies. J of the American Medical Association. 1998;279(15):1200-5.

4. Pirmohamed M, James S, Meakin S. Adverse drug reactions as cause of admission to hospital: prospective analysis of 18,820 patients. British Medical J. 2004;329(7456):15-9.

5. Figueiras A, Tato F, Fontainas J, Gestal-Otero JJ. Influence of physicians' attitudes on reporting adverse drug events: a case control study. Medical Care, 1999;37(8):809-14.

6. Williams D, Feely J. Underreporting of adverse drug reactions: attitudes of Irish doctors. Irish J of Medical Science.1999;168:257-61.

7. Perlik F, Slanar O, Smid M, Petracek J. Attitude of Czech physicians to adverse drug reaction reporting, European Journal of Clinical Pharmacology. 2002;58:367-9.

8. Belton KJ, Lewis SC, Payne S, Rawlins MD. Attitudinal survey of adverse drug reaction reporting by medical practitioners in the United Kingdom, British J of Clinical Pha.1995;39:223-6.

9. Hasford J, Goettler M, Munter KH, MullerOerlinghausen B. Physicians' knowledge and attitudes regarding the spontaneous reporting system for adverse drug reactions, J of Clinical Epi. 2002;55:94550 .

10. Herdeiro MT, Figueiras A, Polo’ nia J, Gestal- Otero JJ. Physicians' attitudes and adverse drug reaction reporting: a case control study in Portugal, Drug Saf, 2005;28:825-33.

11. Hepler CD. Clinical pharmacy, pharmaceutical care, and the quality of drug therapy, Pharmacotherapy. 2004;24:1491-8.

12. Reddy VL. Assessment of Knowledge, Attitude and Perception of Pharmacovigilance and Adverse Drug Reaction (ADR) Reporting among the Pharmacy Students in South India. IOSR Journal of Pharmacy and Biological Sciences. 2014;9(2):34-43.

13. Radhakrishnan R, Vidyasagar S, Varma DM. An Educational Intervention to assess Knowledge
Attitude Practice of pharmacovigilance among Health care professionals in an Indian tertiary care teaching hospital. Int J. Pharm Tech Res. 2011;3(2):678-92.

14. Cosentino M, Leoni O, Banfi F, Lecchini S, Frigo G. Attitudes to adverse drug reaction reporting by medical practitioners in a Northern Italian district. Pharmacol Res. 1997;35:85-8.

15. Figueiras A, Herdeiro MT, Polonia J, Gestal-Otero JJ. An educational intervention to improve physician reporting of adverse drug reactions: a clusterrandomized controlled trial. JAMA. 2006;296:108693.

16. Suveges LG, Gesy KF, Wallace SM, Blackburn JL, Appel WC. Adverse drug reaction reporting part II: evaluation of the Saskatchewan pilot project for a regional reporting program in Canada. Drug Information J.1995;29:581-9.

17. Scolt HD, Thacher-Renshaw A, Rosenbaum SE, Waters WJ, Green M, Andrews LG. Physician reporting of adverse drug reactions: results of the Rhode Island adverse drug reaction reporting project. JAMA. 1990;263:1785-8.

18. Chatterjee S, Lyle N, Ghosh S. A survey of the knowledge, attitude and practice of adverse drug reaction reporting by clinicians in eastern India. Drug Saf. 2006;29:641-2.

19. Bagewadi HG, Venkatadri TV, Nayaka SR. Impact of educational Intervention on Knowledge, attitude, Perceptions of Pharmacovigilance and adverse drug reactions in fifth term medical students and their feedback. Int $\mathbf{J}$ of Res. in Pharmacology \& Pharmacotherapetics. 2015;4(2):164-74.

20. Li Q, Zhang SM, Chen HT, Fang SP, Yu X, Liu D, et al. Awareness and attitudes of healthcare professionals in Wuhan, China to the reporting of adverse drug reactions. Chin Med J. 2004;117:856-61.

Cite this article as: Bagewadi HG, Deodurg PM, Patil BV, Dass AP. Knowledge, attitude, perceptions and assessment of effectiveness of educational intervention on Pharmacovigilance among undergraduate medical students at Gulbarga Institute of Medical Sciences, Kalaburagi, India. Int J Basic Clin Pharmacol 2018;7:103-8. 